\title{
Tidiga syntetiska utställningar i naturhistoriska museer
}

ERIK HEDQVIST

En intressant episod $\mathrm{i}$ de naturhistoriska museernas utställningars historia ägde på 1880-talet rum i det 1881 uppförda nya naturhistoriska museet $i$ London. I en välbekant skildring har Kenneth Hudson gjort sina talrika läsare bekanta med hur läkaren Sir William Flower som direktör från år 1884 vid The Natural History Museum i London lanserade en ny utställningsprincip kallad the new museum idea. Den har stannat i vårt minne som ett program för största möjliga hänsyn till publikens intresse av upplysande, för lekmannen tillrättalagda utställningar. Man skulle visa särskilda skådesamlingar som var skilda från övriga samlingar. Hudson har också fäst uppmärksamheten på Flowers avsikt att i utställningarna belysa naturlagarna och evolutionen. Flowers idé var revolutionerande. Hudson fann att den emellertid inte fick någon tillämpning i de övriga stora naturhistoriska museerna i Europa. De uppfördes ungefär samtidigt som Londons naturhistoriska museum. Hudson gjorde ett kontrafaktiskt antagande: om de i stället uppförts efter museet i London, så skulle de under påverkan av Flowers exempel ha tagit upp och i sina utställningar fullföljt hans idé och därmed uppvisat ett långt mer tillfredsställande resultat. I U.S.A. däremot följde en gynnsammare utveckling. ${ }^{1}$

Vad Hudson berättat väcker nyfikenhet. Han har exemplifierat Flowers idé med en bild av den stora centrala hallen omedelbart innanför entrén till Natural History Museum. Den visar rader av höga montrar vars innehåll kan beskådas från fyra sidor. Bilden förmedlar emellertid inte något av vad utställningsbesökaren kunde se i montrarna. Är detta en utställning som i enlighet med Flowers idé visar evolutio- nen och naturens lagbundenhet? Jag har särskilt lockats av de spår som här kan leda till frågorna om de naturhistoriska museiutställningarnas förhållande till vetenskapen. En utställningskatalog från Londons naturhistoriska museum år 1887 orienterar om utställningen i den stora hallen innanför entrén. Det var en introducerande utställning, ännu inte fullt färdig, medan däremot alla de systematiska 
76 utställningarna i museets båda stora flyglar redan var installerade. Den introducerande utställningen bestod av två delar, dels en som visade strukturen hos olika grupper av djur och växter, kallad Index Museum, dels en del som visade verkningarna av naturlagarna, "the effects of general laws of nature". Det är denna senare del av utställningen som lockat mitt intresse, det är också den som illustrerar Hudsons skildring. Endast en av montrarna i denna del av utställningen hade hunnit färdigställas 1887. Montern innehöll varieteter av olika fåglar, individer av samma art men med olika utseende. Som ett belysande exempel på detta fenomen framhölls två former av kråka som att döma av deras yttre skulle kunna uppfattas som om de tillhörde skilda arter. Dessa båda former kan emellertid åstadkomma en fullt livsduglig avkomma som bildar en övergångsform mellan de båda. I utställningen pågick samtidigt arbetet på en monter som skulle komma att innehålla en grupp duvor avsedda att illustrera variabiliteten hos arter under domesticering. De båda montrarna gav exempel på hur innebörden i begreppet art kommit att vid denna tid rymma problem av växande betydelse. ${ }^{2}$

När utställningen färdigställts, bestod den av 10 höga, i två rader arrangerade fristående montrar med glas på fyra sidor. Utom den ena av de två tidigare montrarna förekom ytterligare en monter som visade exempel på variabilitet under domesticering. Därtill fanns två montrar exemplifierande variation som resultat av kön och årstidsväxlingar. Två montrar illustrerade anpassningen av djurens färg i förhållande till omgivningen, ett resultat av det naturliga urvalet till följd av kampen för tillvaron. Bland de djur som representerade detta fenomen fanns skogshare och fjällräv både i sommardräkt och i vit vinterdräkt. Ytterligare en monter med exempel på skyddande likhet förekom, denna med exempel hämtade från den egyptiska öknen. Två montrar visade exempel på vardera albinism och melanism. ${ }^{3}$ Dessa montrar skulle komma att med oförändrat innehåll stå kvar under flera decennier framöver. ${ }^{4}$

Utställningen saknade en övergripande rubrik, en titel. I katalogen 1887 heter det endast att den skall illustrera allmänna lagar eller intressanta naturhistoriska frågor. ${ }^{5}$ Men det var inte svårt att förknippa utställningen med Darwins evolutionsteori. Till bilden hör att besökaren vägleddes av informativa texter, dels i form av skyltar med korta angivelser av vilket fenomen som framställdes i varje monter, dels utförliga, förklarande texter. Den monter som innehöll djur från den egyptiska öknen, hade en text med rubriken "Adaption of External colouring to the conditions of life". Den fortsatta texten upplyste om hur djurs färg ofta överensstämmer med deras omgivning. Gräsätande djur döljer sig för rovdjuren tack vare färgens anpassning till omgivningen liksom rovdjuren på motsvarande sätt undgår upptäckt när de nalkas sitt byte. ${ }^{6}$

En text i utställningen kunde vara förhållandevis lång och omfatta över 250 ord. ${ }^{7}$ Härigenom gjordes det möjligt att beskriva de fenomen som visades i montrarna. I detta sammanhang är det värt att särskilt lägga märke till hur utställningen inleddes med den monter, som visade olika former av tamduva, det vill säga varieteter av den vilda klippduvan, tamduvans urform. En skylt visade rubriken "Variation in a state of domestication". Det finns olyckligtvis ingen bild som givit möjlighet att tyda vad den till montern knutna texten berättade. De monterade duvorna var arrangerade kring ett duvslag med en korg för deras utfodring. ${ }^{8}$ Det kunde vara ett duvslag $\mathrm{i}$ Darwins eget hem i Down utanför London. ${ }^{?}$ Montern kan betraktas som en hyllning till 


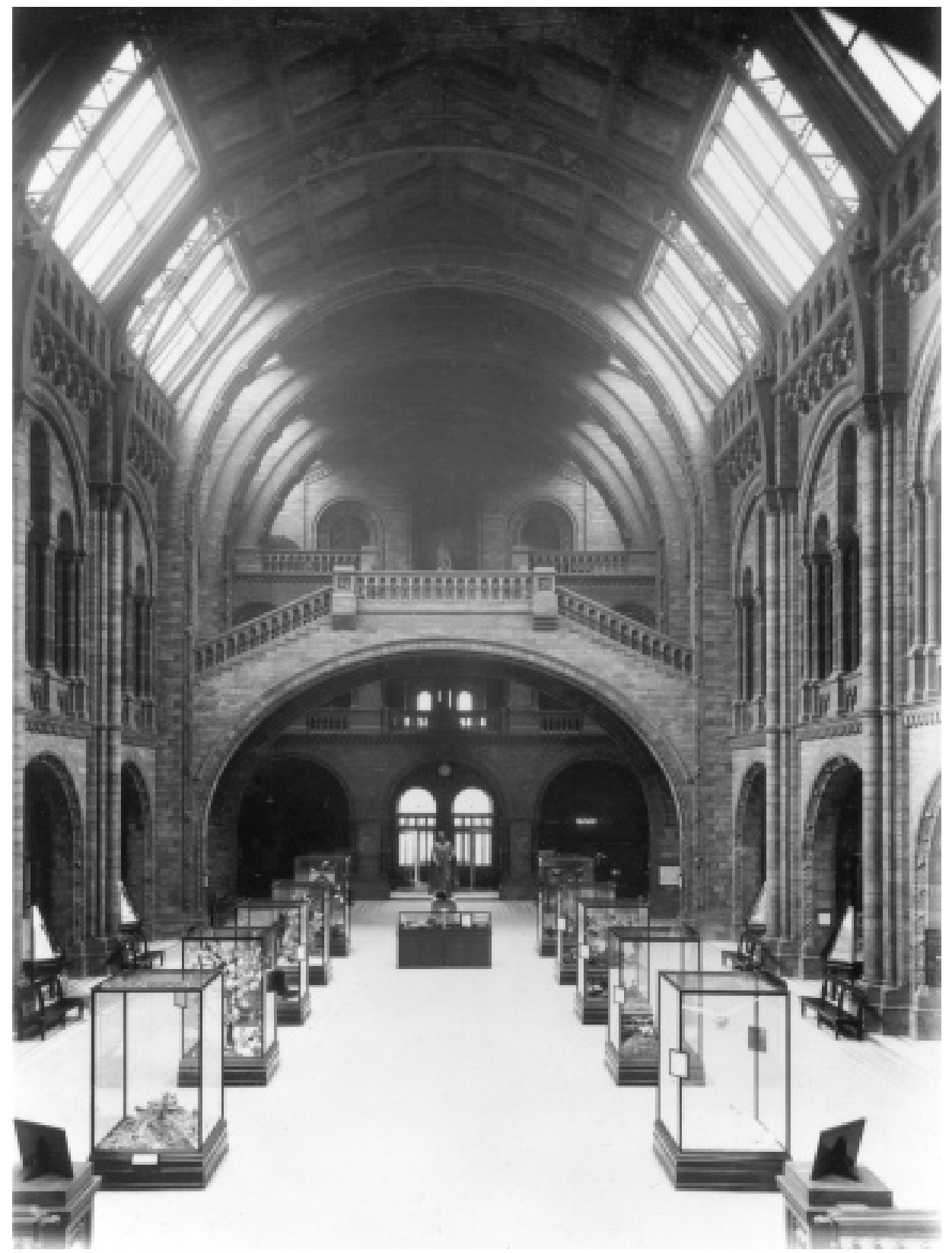

Stora hallen $i$ The Natural History Museum 1901. Bilden visar montrarna med skyltar och texter. Foto: (C) The Natural History Museum, London. 
Darwin som berättat utförligt om sina experiment med duvor. Han hade svårt att i naturen finna direkta belägg för hur urvalet fungerade. Detta var lättare att göra genom iakttagelser vid förädlingen av tamdjur. ${ }^{10}$ Montern var dock än mer mättad av innebörd för den som drog sig till minnes titeln på den bok från 1868, där Darwin tydligt gick emot och avvisade tanken på en allvetande gudomlig skapare, nämligen The Variation of Animals and Plants under Domestication. ${ }^{11}$

Hur ingående återgavs Darwins evolutionsteori i utställningen? Alla de grundläggande principerna för teorin går inte att med bestämdhet påvisa i utställningen. En begränsning av möjligheterna är att de foton, som finns bevarade, inte mer än på något undantag när medgivit att jag kunnat tyda de texter som finns på eller i montrarna. ${ }^{12}$ Vissa av de rubriker, som förekommit på de olika montrarna, har varit möjliga att återfinna på bevarade foton. Man kan här utom de ovan nämnda rubrikerna finna ytterligare två rubriker: "External variation in the two sexes and at different seasons" och "Albinism". ${ }^{13}$

Ernst Mayr har visat hur Darwins teori är ytterst komplicerad och består av premisser och slutsatser i två led. Den första slutsatsen bygger på två sakförhållanden, dels att populationer bortsett från vissa fluktuationer uppvisar stabilitet, dels att naturens resurser är begränsade och i en stabil omgivning förblir konstanta. Slutsatsen är att fler individer produceras än vad omgivningen kan bära. Samtidigt förblir populationens storlek stabil. Det innebär att det måste råda en kamp för tillvaron mellan individerna $\mathrm{i}$ en population med resultat att en vanligen mindre del av varje generations avkomma överlever. På grundval av denna första slutsats jämte ytterligare två premisser bygger sedan de två yttersta slutsatserna, om na- turligt urval och om evolution. Den första av dessa premisser är att individerna inom varje population uppvisar en imponerande variation, den andra att en stor del av denna variation är ärftlig. En fullständig formulering av slutsatsen om naturligt urval kan formuleras som att överlevnad i kampen för tillvaron inte är betingad av slumpen utan delvis beroende av de överlevande individernas ärftliga konstitution. Och den tredje slutsatsen kan formuleras som att det naturliga urvalet över generationerna medför en fortlöpande, gradvis förändring av populationerna, det vill säga till evolution och uppkomst av arter. ${ }^{14}$ Det är inte att vänta att en utställning kan uppvisa och redovisa ett sammansatt resonemang av detta slag. Det är framför allt en öppen fråga om den nödvändiga principen om individernas ärftliga konstitution gått att spåra i utställningen. Ingen av de två texter som varit möjliga att tyda rymmer någon uttrycklig hänvisning till Darwins teori. Redan utan tillgång till de fullständiga texterna i montrarna finner man emellertid att åtskilligt av innehållet knyter an till eller exemplifierar premisser och slutsatser i teorin. Flowers utställning är ett vackert exempel på att det är fullt möjligt att genom kombinationen av föremål i en utställning visa på några av förutsättningarna för evolutionen och dess yttringar. Det var främst två medel som användes, dels kombinationen av föremål som illustrerade bestämda fenomen som förekommer i naturen, dels användningen av längre, förklarande text.

Om man jämför utställningen med de vid denna tid och långt fram i tiden dominerande systematiska utställningarna, där djuren visades utan annan information än släkt- och artnamn och vilken plats de intar i Linnés system, finner man att här råder ett sammanhang av helt annat slag. Det är orsakssamanhangen, kausaliteten, som skapar mening i utställning- 
en från 1880-talet i den stora hallen i Natural History Museum. Det finns en orsak till variationen bland djur under domesticering, nämligen djuruppfödarens urval. Likaså finns ett orsakssamband mellan omgivningen och djurens yttre färg; djurens tillvaro underlättas av denna anpassning. I förhållande till de naturhistoriska museernas gängse systematiska utställningar representerade denna utställning en fundamentalt ny princip. Men det var inte självklart hur den skulle värderas. I en artikel i The Guardian beskrevs den i positiva ordalag, men det är betecknande att den inte ansågs äga samma berättigande som de systematiska utställningarna:

I hallens mitt står en rad standardmontrar ordnade med ett innehåll av mycket vackra serier av utställningsföremål, som visar djurens anpassning till deras naturliga omgivning, deras variation i färg, deras mimicry eller skyddande likhet samt några av de modifikationer som har åstadkommits som resultat av domesticeringen. / ..../ Allt detta är emellertid endast en introduktion till de systematiskt ordnade samlingarna av naturföremål, vilket är de offentliga museernas främsta raison d'être. ${ }^{15}$

Flowers efterträdare E. Ray Lankaster ägnade mycken omsorg åt museets utställningar. ${ }^{16} \mathrm{På}$ hans initiativ tillkom montrar som visade modeller att tsetsefluga och myggor i förstoring tillsamman med de parasiter på dessa insekter som sprider sömnsjuka och malaria. ${ }^{17}$ Fullt färdig bestod denna utställning av ett flertal montrar som visade ytterligare ett antal insekter och sjukdomsbärande parasiter. ${ }^{18}$ Man skall även lägga märke till att någon gång före 1930-talet tillkom i en sal bakom den stora hallen en utställning som ägnades husdjuren, deras härstamning och förädling. Här kunde besökaren ta del av resultaten av ett antal experiment med korsningar och hur dessa kunde tolkas enligt Mendels teori. ${ }^{19}$ Båda dessa utställningar visa- de på större samband, orsaker bakom sjukdomars spridning eller resultaten av en påvisad lagbundenhet.

Står någon annan, jämförbar utställning att finna vid denna tid? Jag har i det föregående återgivit hur Hudson inte kunnat finna att något av de stora europeiska naturhistoriska museerna utvecklades i den riktning Flower anförde. Hudson framhöll däremot de något senare tillkomna museerna i U.S.A. med deras friare förhållande till traditionen. ${ }^{20}$ Man kan mycket riktigt där finna ett intressant exempel, det är i New Yorks stora naturhistoriska museum, The American Museum of Natural History. Där fanns vid tiden före första världskriget och framåt en utställningssal uppkallad efter Charles Darwin. Den rymde två delar varav den ena visade "certain facts made clear by Darwin". Här förekom dels variationen under domesticering illustrerad av hund, duva och tamhöns, medan kampen för tillvaron var återgiven genom en grupp åkersorkar omgivna av deras fiender "and yet continuing to maintain an existence by virtue of its great birth rate." ${ }^{\prime 21}$ Ett par år senare hade utställningen kompletterats med en framställning av variationen i naturen, exemplifierad av bland andra finkar tillhörande släktet Geospiza från Galapagosöarna. ${ }^{22}$ Det var fåglar av detta släkte som Darwin under sin resa med "Beagle" upptäckt under det fem veckor långa besöket på dessa öar. Finkarna liksom jättesköldpaddorna och många andra arter varierade i form från den ena ön till den andra. ${ }^{23}$ Darwin hade iakttagit hur många av de stora, omfattande släktenas arter påminner om varieteter. De är mycket nära men inte likformigt besläktade med varandra och har begränsade utbredningsområden. När Darwin och andra på Galapagosöarna jämförde fåglarna från de olika öarna, slogs han av hur vacklande distinktionen är mellan 
80 art och varietet. ${ }^{24} 1920$ rymdes i utställningen grupper som illustrerade kampen för tillvaron, de starkastes överlevnad, geografisk spridning och variation i naturen och under domesticering. ${ }^{25}$

1930-talet och tiden fram till efter andra världskriget syns ha varit en tid av stagnation de båda museerna i London och New York. 1943 rapporterade The American Museum of Natural History om en kommitté som tillsatts för att planera för museets framtid. Bakgrunden var att man ansåg att museet i likhet med andra naturhistoriska museer nått ett kritiskt stadium i sin utveckling, "a critical stage in the development of their functions and their services to society”. ${ }^{26}$ Något år senare tecknades $\mathrm{i}$ museets årsberättelse ett historiskt perspektiv på de aktuella frågorna:

När museet först började insamlingen till dess stora samlingar fanns fortfarande så många och nya och uppseendeväckande ting att upptäcka att blotta observationen, dokumentationen och jämförelsen mellan de fantastiska variationerna i form och färg, som naturen frambringade, tycktes tillräckligt för att tillfredsställa både forskaren och lekmannen som besökte museet.

Museet hade nu att möta önskemålen om utställningar som tolkar de inre mekanismerna bakom funktionerna i naturen. ${ }^{27}$ Bristen på medel skulle dock göra sig gällande många år efter krigsslutet. Först kring 1950 kunde museet förverkliga planerna på en förnyelse av utställningarna. Den 1 november påbörjades arbetet på tre nya utställningar: The Hall of Landsape, The Hall of Forestry och The Hall of Botany. ${ }^{28}$ Våren 1951 öppnades Felix M. Marburgs minneshall med en utställning som var avsedd att visa grundläggande fakta om livet i naturlig omgivning och under människans påverkan. Utställningen förklarade hur blommor pollineras och utvecklas till frukt, varför man gödslar åkern. Den visade relationen jord och planta. Utställningen lanserades som exempel på en ny tendens inom museet i riktning mot en vidgning av begreppet naturhistoria. $^{29}$

Det är svårt att finna belägg för att det naturhistoriska museet i London under mellankrigstiden gjorde några större nya framsteg på utställningsområdet. Efter andra världskriget följde en kritisk period för museet, med ständig brist på pengar och därtill otillräckliga utrymmen för samlingar och vetenskaplig verksamhet. ${ }^{30}$ Så sent som 1969 erinrade museets direktör om att många av museets utställningar alltjämt var "taxonomically based", det vill säga tillhörde gamla sortens systematiska utställningar. Dilemmat var att i ett traditionstyngt museum föra in den nya utvecklingen inom cellbiologin. Något beslut hade ännu inte tagits i frågan, om dessa utställningar skulle ersättas med nya. Det skulle vara tilltalande att utgå från kunskaperna om aminosyrorna och cellstrukturerna. Om man däremot ville starta på välbekant mark, skulle ekologin ligga väl till. Ett par månader senare antog styrelsen för museet ett viktigt principbeslut i frågan om utställningarnas innehåll. Ämnesområdet skulle vidgas. Det skulle inte längre vara begränsat till den äldre, morfologiskt inriktade biologin; även den experimentella biologins rön skulle ges utrymme i utställningsprogrammet. $\mathrm{Mu}$ seet skulle visa utställningar som handlade såväl om evolutionen som om molekylärbiologi, fysiologi och ekologi. ${ }^{31}$ Det var i likhet med Flowers utställning i centralhallen i Londons naturhistoriska museum utställningar inom områden, där sammanhang skapas framför allt med tillämpning av kausal slutledning.

Jag har visat hur det i de båda museerna i London och New York under tiden före och efter sekelskiftet 1900 visades två utställningar 
som till skillnad från majoriteten av utställningar visade på sammanhangen bakom de olika formerna inom djurriket. Vi kan karakterisera de båda utställningarna som syntetiska. Alma Wittlin urskiljde i sitt klassiska arbete The Museum (1949) två tendenser i museiutställningarna under tidigt 1900 -tal, den ena i analytisk och den andra i syntetisk riktning. Den analytiska var förhärskande på det naturhistoriska området, den ledde till att föremålen ordnades enligt släkten under fastställda klasser och underavdelningar, medan den syntetiska riktningen sökte inordna föremålen i någon form av förening av olika enheter till en helhet, en syntes. ${ }^{32}$

Frågan är varför de båda tidiga syntetiska utställningarna inte fick större omdelbar inverkan på utställningspolitiken i de båda museerna. Förklaringar kan sökas i olika riktningar, men jag skall här lägga åt sidan de förklaringar som kan sökas utanför museerna. Jag vill framför allt erinra om hur museerna $\mathrm{i}$ sin vetenskapliga aktivitet i stor utsträckning var bundna vid uppgiften att samla material och att artbestämma och klassificera detta. Här ett mått på den osannolikt stora omfattningen av insamlingen: de vetenskapliga samlingarna enbart av däggdjur ökade vid American Museum of Natural History under verksamhetsåret 1950-1951 med 5760 föremål. Som ytterligare exempel kan nämnas att till museets avdelning för geologi infördes samma år från undersökningar i Texas inte mindre än 15 ton kalksten innehållande ryggradslösa djur från den permiska perioden. Man talade om systematiken och klassifikationen som museets ständiga uppgift. ${ }^{33}$ Det är rimligt att anta att medarbetarna vid museerna till följd av sina stora med artbestämning och klassifikation förenade uppgifter var benägna att främst följa det analytiska tänkandets banor. Till detta tänkan- de hörde metoden att nå kunskap via beskrivning och generalisering av upprepad observation av samma fenomen. Beskrivning och induktion var ledande metod inom biologin ett gott stycke in på 1900-talet. Det var till stor del denna metod som gav berättigande åt den viktorianska erans utomordentliga blomstring av biologiska och geologiska samlingar och vid slutet av 1800-talet ledde till uppförandet av de stora nationella museer som skulle härbärgera dessa samlingar. ${ }^{34}$ Det är emellertid två processer som stödjer förmågan att nå kunskap om världen, utom klassifikation också kausal slutledning. Kausalt tänkande är ett av de effektivaste sätten att finna sammanhang i den värld vi lever i. ${ }^{35}$ Det var intresset för kausal slutledning som låg bakom de tidiga syntetiska utställningar jag studerat och som återkom och ledde till ambitionen efter andra världskriget till förnyelse av utställningarna vid de båda museerna i London och New York. Man har att göra med två skilda tanketraditioner för förklaring av fenomenen, den aristoteliska och den galileiska. I den aristoteliska traditionen är strävandena att förklara förbundna med ett teleologiskt eller finalistiskt synsätt. Galileisk tradition löper parallellt med kausalt eller mekanistiskt synsätt att förklara och förutsäga fenomenen. Valet av vilken tradition vi ansluter oss till är, menar Georg Henrik von Wright, "a choice of a point of view which cannot be further grounded". ${ }^{36}$ De många medarbetarna vid de naturhistoriska museerna var knutna till en tradition som allvarligt försvårade möjligheten att anamma ett kausalt eller mekanistiskt synsätt. Det är betecknande att Flower, banbrytaren för de syntetiska utställningarna inte från början tillhörde museiprofessionen utan var läkare och därmed mer obunden av den tradition inom tänkandet som rådde inom museerna. 


\section{KäLLOR OCH LITTERATUR}

\section{Arkivmaterial}

The American Museum of Natural History. Department of Library Service. Photographic Collection.

The Natural History Museum. London. Museum Archives: Photographs.

\section{Press}

The Illustrated London News, 10/12 1887.

The Guardian, 1/12 1906.

Tryckta källor och litteratur

The American museum of Natural History. Seventyfourth Annual Report for the Year 1942. New York, 1943.

, Seventy-fifth Annual Report for the Year 1943.

New York, 1944. , Seventy-ninth Annual Report for the Year

1948/1949. New York, 1949. , Eighty-second Annual Report. July 1950, Through June, 1951. New York, 1951.

The British Museum (Natural History) Illustrated Guide to the Exhibition Galleries. London, 1931. Aspelin, Gunnar, Tankens vägar: En översikt av filosfiens utveckling. Del II.(1958) Lund, 1977.

Darwin, Charles, Om arternas uppkomst genom naturligt urval. (1859) Översättning. Stockholm, 1974.

Dunbar, Robin, The Trouble with Science. London, 1995.

Guide, A General to The British Museum (Natural History). London, 1887.

Guide, A General to The British Museum (Natural History). London, 1903.

Hudson, Kenneth, Museums of Influence. Cambridge, (1987) 1988.

Lester, Joe, E. Ray Lankaster and the Making of Modern British Biology. Ed. Peter Bowler. U.o.,1995.

Lindroth, Sten, Charles Darwin. U.o., 1946.

Lucas, Fredric A. et al, General Guide to the Exhibition Halls of The American Museum of Natural
History. New York, 1914.

, General Guide to the Exhibition Halls of The

American Museum of Natural History. New York, 1918.

, A First Chapter in Natural History. (The

American Museum of Natural History Guide

Leaflet no. 51). New York, 1921.

Mayr, Ernst, The Growth of Bilogical Thought: Diversity, Evolution, and Inheritance. Cambridge,

Massachusets, 1982.

Stearn, William, T., The Natural History Museum at South Kensington: a History of the British Museum (Natural History) 1753-1980. London, 1981.

Wittlin, Alma, The Museum: Its History and its Tasks in Education. London, 1949.

Wright, Georg, Henrik, von, Explanation and Understanding. London, 1971.

\section{SUMMARY}

\section{Early synthetic exhibitions in natural history museums}

Many of us are by our reading of one of Kenneth Hudson's well known texts familiar with William Flower's new museum idea. One of its principles is that natural history museums should in their exhibitions shed light upon the natural laws and the evolution. Hudson has illustrated his report on this issue with a photo, which shows an exhibition in the main hall of The Natural History Museum in London. Intrigued by Hudsons text I have studied this exhibition especially. Its first exhibits were from the year of 1887.Photos in the archives of the museum demonstrate that the exhibition is to be regarded as an illustration of phenomena which might be explained by Darwin's theory of evolution. A similar exhibition existed at about the same time at The American Museum of Natural History in New York. These exhibitions were early instances of synthetic exhibitions illustrating the causal connection behind the phenomena. Contrary to what one might expect the two examples had little effect on 
the exhibition policy of the museums during the following years. Not until after 1950 did exhibitions, in which the causal connection made the coherence of the exhibitions, come to the front, at first at the museum in New York, later in London. I suggest that the museum method of explaining the phenomena was connected to the accession of collections, and bound to description and classification, the Aristotelian tradition. Another tradition, the Galilean, runs parallell to the causal or mecanic way of explaining and predicting the phenomena. According to Georg Henrik von Wright which one of the two traditions to which we join is a "choise of a point of view which cannot be further grounded". In these circumstances we easily understand the reluctance of the museum people to enter the synthetic exhibition trend.

\section{NOTER}

1. Kenneth Hudson, Museums of Influence. Cambridge, (1987), 1988, 68-73.

2. A General Guide to The British Museum (Natural History). London, 1887, 22.

3. A General Guide to The British Museum (Natural History). London, 1903, 9-13, 16.

4. Vid början av 1930-talet fick utställningen samsas med två ståtliga monterade elefanter utöver de tidigare montrar som visade insekter och sjukdomsbärande parasiter. British Museum, Illustrated Guide to the Exhibition Galleries. London, 1931, 25.

5. A General Guide to The British Museum (Natural History). London, 1887, 22.

6. The Natural History museum, Museum Archives: Photographs Vol 1 nr 171 "Egyptian Desert Animals".

7. Ibid., nr 180 "Case illustrating Adaption of Colour to Surroundings".

8. Ibid., nr 175 "Pigeon Case".

9. Montern observerades karakteristiskt nog $\mathrm{i}$ en artikel under rubriken "The Great Mr Darwin" i
The Illustrated London News 10/12 1887.

10. Charles Darwin, Om arternas uppkomst genom naturligt urval. (1859) Översättning. Stockholm, 1974, 16-23: Darwin var intresserad av tidens vetenskapsteoretiska frågor och diskussionen kring experimentets roll, då det gällde att pröva sanningsvärdet hos en hypotes. I detta perspektiv betraktade han den artificiella selektionen som en accelererad process analog med selektionen $\mathrm{i}$ naturen; den artificiella selektionen tjänade som dess experimentella bevis. Ernst Mayr, The Growth of Biological Thought: Diversity, Evolution, and Inheritance. Cambridge, Massachusets, 1982, 486-487.

11. Ibid., 402.

12. I arkivet vid The Natural History Museum har jag funnit ett dussin foton som mer eller mindre tydligt återger innehållet i de tio höga montrarna i centralhallens mitt. För min orientering i arkivet har jag tacksamt emottagit ovärderlig hjälp av arkivarien vid The Natural History Museum John Thackray.

13. The Natural History Museum, Museum Archives: Photographs Vol $1 \mathrm{nr} 181$ "Case illustrating variations in the two sexes", Vol $1 \mathrm{nr} 177$ "Case illustrating albinism".

14. Mayr 479-480.

15. The Guardian, 1/12 1906.

16. William T. Stearn, The Natural History Museum at South Kensington: A History of the British Museum (Natural History) 1753-1980. London, 1981, 77, 93-94.

17. A General Guide to the British Museum (Natural History). London, 1903, 14-17. Lankaster planerade tillfälliga utställningar, bland andra över tsetseflugan och dess parasiter. Joe Lester, E. Ray Lankaster and the Making of Modern British Biology. Editited by Peter Bowler (British Society for the History of Science) 1995, 139.

18. Illustrated Guide to the Exhibition Galleries. London, 1931, 21-32. 
19. Ibid., 58-59: Redan 1907 erhöll museet i gåva en serie möss som var resultat av korsning mellan en japansk "walzing mouse" och vanlig vit mus. En tavla med monterade möss visar hur de speciella anlagen är fördelade i generationerna F1-F3. The Natural History Museum, Museum Archives: Photographs. Vol 2 nr 1029.

20. Hudson, 73.

21. Fredric A. Lucas et al., General Guide to the Exhibition Halls of the American Museum of Natural History. New York, 1914, 43. "Kampen för överlevnaden" var en dramatisk framställning där en samling sorkar syns omgivna av sin många fiender, överst en uggla, en huggorm är på väg att sluka en av sorkarna. The American Museum of Natural History, Department of Library Service, Photographic Collection Neg. \# 38085, 1920, J. Kirschner, "The Struggle for Existence".

22. Fredric A. Lucas et al., General Guide to the Exhibition Halls of The American Museum of Natural History. New York, 1918, 33.

23. Sten Lindroth, Charles Darwin. U.o., 1946, 40 43.

24. Darwin, 35, 38.

25. Fredric A. Lucas, A First Chapter in Natural History. (The American Museum of Natural History Guide Leaflet No. 51). New York, 1920, 2.

26. The American Museum of Natural History. Seventy-fourth Annual Report for the Year 1942. New York, 1943, 14.

27. The American Museum of Natural History. Seventy-fifth Annual Report for the Year 1943. New York, 1944, 21-22.
28. The American Museum of Natural History. Seventy-ninth Annual Report for the Year 1948/1949. New York, 1949, opaginerad.

29. The American Museum of Natural History, Eightysecond Annual Report. July 1950, Through June, 1951. New York, 1951, 8-9.

30. Stearn, 333-334, 365, 376-385.

31. Ibid., 367.

32. Alma Wittlin, The Museum: Its History and its Tasks in Education. London, 1949, 142-143: De båda begreppen analytisk och syntetisk låter sig ledas tillbaka till Galileo Galilei. Forskaren följer enligt honom två vägar, analysens och syntesens (metodo risolutivo och metodo compositivo). Dels upplöser forskaren fenomenen i deras enkla element, studerar dem var för sig och uppställer en hypotes om deras inbördes relation, dels kombinerar forskaren elementen med varandra och prövar om resultatet stämmer med ett $\mathrm{i}$ förväg gjort antagande. Gunnar Aspelin, Tankens vägar: En översikt av filosofiens utveckling. Del II. (1958) Lund, 1977, 41.

33. The American Museum of Natural History. Eightysecond Annual Report. July, 1950, Through June, 1951. New York, 1951, 27-28.

34. Robin Dunbar, The Trouble with Science. London, 1995, 18, 58, 85.

35. Ibid., 58.

36. Georg Henrik von Wright, Explanation and Understanding. London 1971, 2-3, 32.

Eric Hedqvist är doktorand i museologi vid Institutionen för kultur och medier, Umeå universitet, S-901 87 Umea. 